\title{
BMJ Open Impact of neighbourhood walkability on the onset of multimorbidity: a cohort study
}

\author{
John Sina Moin (D) ," Richard H Glazier (D) , ${ }^{2,3}$ Kerry Kuluski (D) , ${ }^{4}$ Alex Kiss, ${ }^{5,6}$ \\ Ross Upshur (iD) ${ }^{1,7}$
}

To cite: Moin JS, Glazier RH, Kuluski K, et al. Impact of neighbourhood walkability on the onset of multimorbidity: a cohort study. BMJ Open 2021;11:e045890. doi:10.1136/ bmjopen-2020-045890

- Prepublication history and additional supplemental material for this paper are available online. To view these files, please visit the journal online (http://dx.doi.org/10.1136/ bmjopen-2020-045890).

Received 19 October 2020 Revised 03 April 2021 Accepted 06 April 2021
Check for updates

(C) Author(s) (or their employer(s)) 2021. Re-use permitted under CC BY-NC. No commercial re-use. See rights and permissions. Published by BMJ.

For numbered affiliations see end of article.

Correspondence to Dr John Sina Moin; sina_moin@live.com

\section{ABSTRACT}

Multimorbidity has become highly prevalent around the globe and been associated with adverse health outcomes and cost of care. The built environment has become an important dimension in response to obesity and associated chronic diseases by addressing population sedentariness and low physical activity.

Objective The aim of the following study was to examine whether there was an increased risk for multimorbidity for those living in less walkable neighbourhoods. It was hypothesised that participants residing in less walkable neighbourhoods would have a higher risk for multimorbidity. Setting City of Toronto and 14 neighbouring regions/ municipalities within Ontario, Canada.

Participants Study participants who had completed the Canadian Community Health Survey between the year 2000 and 2012, between 20 and 64 and 65 and 95 years of age, residing within a neighbourhood captured in the Walkability Index, and who were not multimorbid at the time of interview, were selected.

Intervention The Walkability Index was the key exposure in the study, which is divided into quintiles (1-least, 5-most walkable neighbourhoods). Participants were retrospectively allocated to one of five quintiles based on their area of residency (at the time of interview) and followed for a maximum of 16 years.

Primary outcome measure Becoming multimorbid with two chronic conditions.

Secondary outcome measure Becoming multimorbid with three chronic conditions.

Results Risk for multimorbidity (two chronic conditions) was highest in least compared with most walkable neighbourhoods with an HR of 1.14 (95\% Cl: 1.02 to 1.28 , $\mathrm{p}=0.0230$ ). While results showed an overall gradient response between decreased walkability and increased risk for multimorbidity, they were not statistically significant across all quintiles or in the older-adult cohort (65-95 years of age).

Conclusion Study results seem to suggest that low neighbourhood walkability may be a risk factor for multimorbidity over time. More studies are needed to examine whether neighbourhood walkability is a potential solution for multimorbidity prevention at the population level.

\section{BACKGROUND}

A quarter of Canadians 40 years and older are multimorbid, which is approximately over 5 million people. ${ }^{1}$ Major health-related
Strengths and limitations of this study

- This study was a retrospective cohort design with a relatively large sample size and long follow-up time.

- Study outcomes were based on universal healthcare administrative databases and not self-reported conditions.

- A complex sampling strategy and bootstrap weights provided by Statistics Canada ensures representative and generalisable results.

- The Walkability Index used was only available for more urban settings within Ontario, Canada, and not rural areas.

- The Walkability Index was assigned to participants at the time of interview and was kept consistent throughout the follow-up time.

consequences of multimorbidity (MM) are disability, functional decline, poor quality of life and high healthcare costs. ${ }^{2-6}$ According to a Canadian report, both direct and indirect costs associated with chronic diseases amounted to \$C53.19billion (2010 CAD) dollars annually in Canada. ${ }^{7}$ In Ontario, direct healthcare costs linked to the top four chronic diseases (cancers, cardiovascular diseases, chronic lower respiratory diseases and diabetes) amounted to \$C10.5 billion annually in 2018 CAD dollars. ${ }^{8}$ There is growing evidence that urban environments that discourage walking and other physical activities (PAs) have contributed to high rates of obesity and chronic diseases (eg, type 2 diabetes) ${ }^{9-14}$ Staying active and engaging in regular PA are widely accepted as effective preventive measures for a wide variety of common chronic diseases, across age, gender, ethnic and socioeconomic groups. ${ }^{15} 16$ However, most Canadians are not meeting PA guidelines (92\% of youth aged $5-17$ years; $82 \%$ of adults $18-79$ years).$^{17}$

In the last decade, mounting evidence has placed focus on the built environment as a viable area for public health interventions, 
targeting population sedentariness and low PA. ${ }^{9} 1118$ Among the four domains of PA (eg, leisure, household/ domestic, occupational/school, transportation) identified by Pettee Gabriel et $a l l^{19}$ transportation-related PA (walking or biking to/from destinations) offers the greatest opportunity for sustainable increase in daily PA, especially for lower income households. ${ }^{20-23}$ Transportation-related PA can increase daily movement through active travel and through transit-induced PA. A study by Glazier et $a l^{10}$ showed that individuals living in more walkable areas were more than twice as likely to walk, cycle or use public transit and were significantly less likely to drive or own a vehicle compared with those living in less walkable neighbourhoods. Moreover, individuals living in the least walkable areas were up to one-third more likely to be obese or to have diabetes. ${ }^{10}$ Another study by Creatore $e t a t^{\theta}$ found that the prevalence and 12-year incidence of overweight and obesity were lower in the most walkable neighbourhoods versus less walkable areas. A Cochrane review examining community-wide interventions for promoting increased PA concluded that while results on various interventions were non-conclusive, walking was the more widely adopted PA within permissive built environments. ${ }^{24}$

While the relationship between neighbourhood walkability, active transportation and walking-induced-PA is becoming clearer, ${ }^{10} 111425-27$ the impact on incidence of MM has not been explored. While studies have examined neighbourhood walkability in relation to single chronic conditions and reaching recommended daily PA guidelines, ${ }^{9} 1821$ 28-30 to date, there have been no studies examining the impact of neighbourhood-level walkability on incidence of MM. The following study aims to address this gap by analysing up to 16-year incidence of MM within 15 Southern Ontario municipalities. It is hypothesised that high walkable areas will have higher walking-related PA and consequently lower incidence risk for MM. The association between material depravation and prevalence of MM was shown in a previous study. ${ }^{31}$ As such, the interaction between area-level walkability and material depravation will also be analysed. It is hypothesised that those who live in the least deprived and most walkable areas will have the lowest risk of MM.

\section{METHODS}

\section{Study population and setting}

The following study design was a retrospective cohort study. A time to event analysis was conducted to compare the occurrence of MM during a 16-year follow-up period across urban neighbourhoods among different levels of walkability. This study was conducted within Southern Ontario metropolitan areas, which includes 15 municipalities (Hamilton, London, Ottawa, Toronto and surrounding municipalities), and a combined population of over 7 million residents. ${ }^{9}$ A combination of data collected from administrative healthcare databases, provincial and national surveys, were used to derive population sociodemographics, health behaviours and MM estimates. Deidentified survey respondents between the ages of 20 and 95 were allocated to a walkability quintile (ie, score) based on postal codes for their area of residence. The attribution of walkability to each neighbourhood was at the 'dissemination area' (DA) level. DA 'is a small, relatively stable geographic unit composed of one of more adjacent dissemination blocks with an average population of $400-700$ persons based on data from previous Census of Population Programms'. ${ }^{32}$ DA is the smallest standard geographic unit for which all census data are disseminated. ${ }^{32}$ Postal codes for each survey respondent were used to connect them and their dwelling to a DA and associated walkability quintile as the key exposure over time.

\section{The ON-Marg Index (area-level measure for socioeconomic status and marginalisation)}

The ON-Marg Index was developed using 42 census variables and currently available for the year 2016. The ON-Marg has four dimensions: material deprivation (composite measure of income, education, singleparent families, housing quality), residential instability (composite measure of dwelling/family characteristics, neighbourhood quality and cohesiveness), ethnic concentration (area-level measure of residents who are recent immigrants and visible minorities) and dependency (adults who are unemployed, unable to work, in unpaid professions). ${ }^{33}$ Each dimension is organised into quintiles, with quintile 1 representing those least marginalised to quintile 5 (most marginalised). A stratified analysis was conducted using material deprivation as it was strongly associated with $\mathrm{MM}$ in a previous study. ${ }^{31}$

\section{Canadian Community Health Survey}

This study used several linked survey cycles $(2000 / 2001$; 2003/2004; 2005/2006; 2007/2008; 2009/2010; 2011/2012;) from the Canadian Community Health Survey (CCHS), to control for sociodemographic and behavioural variables for all eligible residents of Southern Ontario, residing within urban metropolitan areas (with a walkability quintile) between 20 and 95 years of age. The term 'linked' implies that survey respondents' real healthcare utilisation data has been linked to their survey with a unique encrypted id, referred to as IKN (ICES Key Number). The CCHS is a cross-sectional population health survey that includes Canadians aged 12 years and older but does not include those living in long-term care facilities, reserves, full-time members of the Canadian Armed Forces or civilian residents on military bases. ${ }^{34}$ The survey was designed to derive estimates at the national and provincial levels for various health regions in Canada. ${ }^{34}$ A complex multi-stage allocation and sampling strategy ensures relative equal weighting to health regions and the provinces. ${ }^{34}$ More details on the sampling methodology of CCHS are available elsewhere. ${ }^{35}$

For this analysis, a CCHS-derived multivariable model based on sociodemographic factors (age, sex, marital 
status, education, income), health behaviours (smoking, physical inactivity) and other relevant risk factors (high life-stress, self-perceived health) was used within the Cox regression component. This enabled a degree of control over confounders while examining the walkability exposure on MM over time.

\section{Walkability Index}

A validated composite Walkability Index was used to derive differing levels of neighbourhood walkability for each DA. The Walkability Index is a product of literaturederived variables, various data sources (census, land use, retail and public service data) and geographic information systems. ${ }^{18}$ Using principle component analysis, population density (number of persons per square kilometre), dwelling density (number of occupied residential dwellings per square kilometre), street connectivity (number of intersections with at least three converging roads and/or pathways) and availability of walkable destinations (number of retail stores, services-banks, libraries, community centres, etc within 800 metres or roughly $10 \mathrm{~min}$ walk) were identified and equally weighted. ${ }^{918}$ Index scores are positively associated with increased walking, cycling, public transit use and inversely with car ownership and driving. ${ }^{918}$ Detailed information regarding the index and its creation can be found elsewhere. ${ }^{36}$ DAs were ordered equally from least (quintile 1 $(\mathrm{Q} 1)$ ) to most (quintile 5 (Q5)) walkable and assigned to each person based on their postal code. The Walkability Index has been validated and shown to be relatively stable over time. As such, the walkability exposure is deemed to be stable over time and therefore not treated as a timedependent variable. ${ }^{9}$

\section{MM and derived chronic conditions from ICES Health Administrative databases}

Cases of MM were obtained using distinct health administrative databases and MM macro at ICES. Occurrence of MM event was defined as having two (2) and three (3) chronic conditions from the list of 18 diseases (acute myocardial infarction, asthma, cancers, cardiac arrhythmia, chronic coronary syndrome, chronic obstructive pulmonary disorder, congestive heart failure, diabetes, hypertension, inflammatory bowel disease, mood and anxiety disorders, other mental illnesses (schizophrenia, delusions and other psychoses, personality disorders and substance abuse), osteoarthritis, osteoporosis, renal failure, rheumatoid arthritis and stroke (excluding transient ischaemic attack)). While the two-count definition for incidence of MM can serve as a general definition, the differentiation between occurrence of two and three conditions can help identify more high-need patients. ${ }^{37}$ List of chronic diseases were chosen for their high prevalence, social and economic burden and clinical relevance. ${ }^{38}$ In consultation with experts in the field, it was concluded that 17 of the 18 included conditions were subject to small or large benefits from increased PA. Inflammatory bowel disease was the only condition which had little association with PA. However, it was decided against modifying the list of conditions, therefore, all 18 conditions were kept within the MM macro. For more information on the algorithm and allocation of chronic diseases refer to the following documents. ${ }^{38} 39$

\section{Statistical analysis}

Summary statistics frequency and percentages for nominal measures, median for continuous measures were used to describe the data sample. The primary outcome was the onset risk of MM over time. The main exposure over time was the Walkability Index, expressed in quintiles (1-least walkable; 5 -most walkable). The cause-specific Cox proportional hazard model (Cox model) was used to conduct the survival analysis and model time to MM (accounting for censoring and death as competing risk). The event was defined as time from the index period (ie, interview date) to case-definition MM (two chronic conditions, for sensitivity analysis three chronic conditions). A 2-year lookback prior to index date was applied to identify patients already multimorbid, for exclusion. All respondents of CCHS with zero or one chronic condition (at their time of interview) were identified (by administrative data) and observed till either MM, death, loss of Ontario Health Insurance Plan (OHIP) eligibility, loss to follow-up or end of study. Death was treated as a competing risk and others were censored at the time of loss to follow-up or end of study. Minimum follow-up time was 6 years, and the maximum follow-up time was approximately 16 years. Cases with missing values were excluded from analysis.

The following confounders were controlled for in the analysis (eg, age, sex, education, income, marital status, smoking, stress, PA, self-perceived health). In SAS, the PROC SURVEYPHREG procedure was used to model time to MM. The 95\% CI and $\mathrm{p}$ values were calculated using 500 bootstrap weights provided by Statistics Canada. All estimates are weighted using sampling weights. A stratified analysis was conducted to see the impact of neighbourhood walkability in each material deprivation quintile (1-least deprived; 5 -most deprived), provided by the Ontario Marginalization Index. The time to event analysis was stratified by age (20-64 and 65-95 years old) and number of conditions (two-count and three-count event). Model estimates were presented as HRs and their associated 95\% CIs. The threshold for statistical significance was $\mathrm{p}<0.05$ and all tests two-sided. The analyses were conducted using SAS Enterprise V.7.1.

\section{Patient and public involvement}

No patients involved.

\section{RESULTS}

\section{Population and neighbourhood characteristics}

The total data sample in the study was $n=26808$ individuals, of which $n=24536$ were between the ages of 20 and 64 years. Over a third of the population in the most walkable neighbourhoods (Q5) were between the ages of 20 
Table 1 Study variables by neighbourhood walkability quintiles

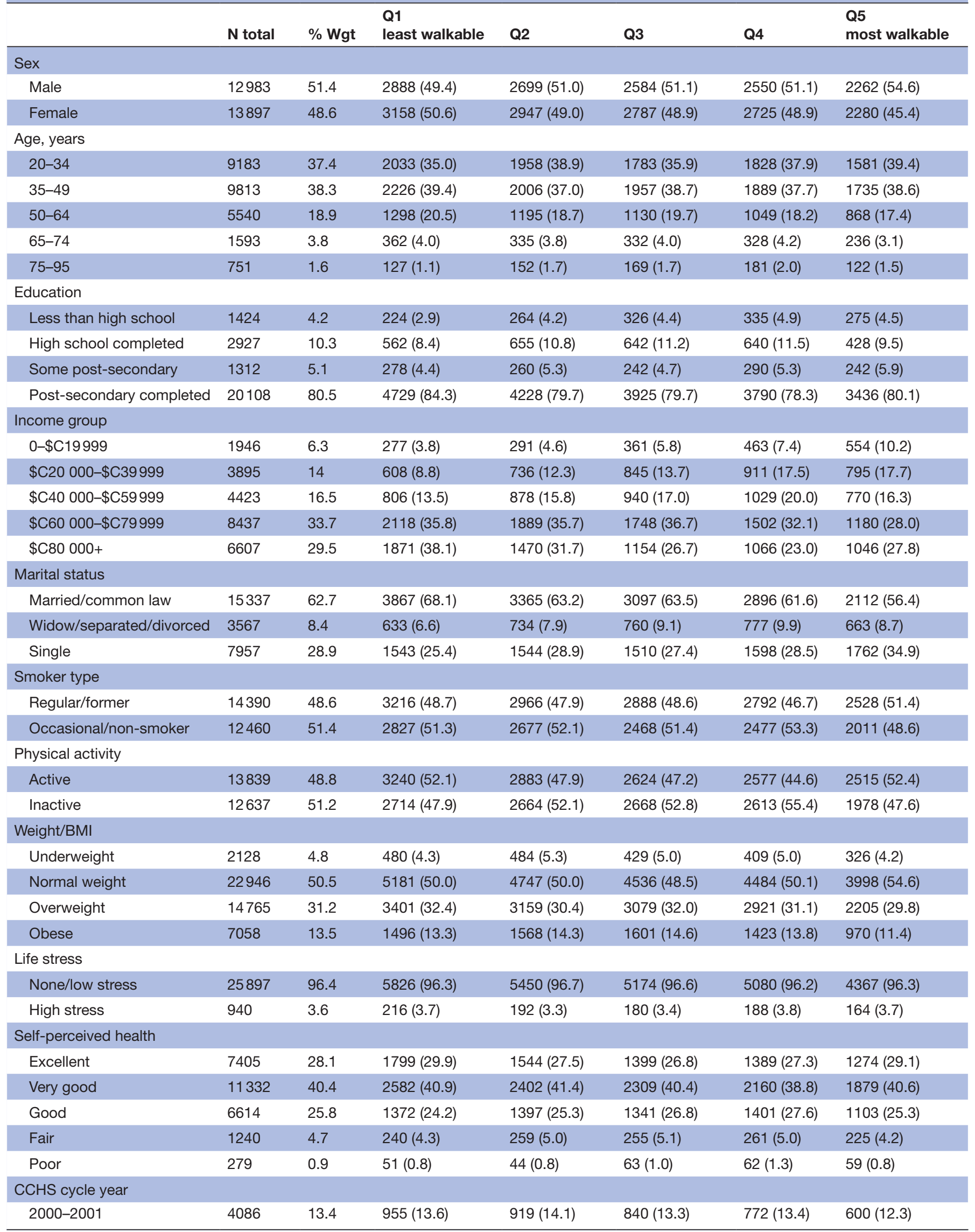


Table 1 Continued

\begin{tabular}{|c|c|c|c|c|c|c|c|}
\hline & $\mathbf{N}$ total & $\% \mathbf{W g t}$ & $\begin{array}{l}\text { Q1 } \\
\text { least walkable }\end{array}$ & Q2 & Q3 & Q4 & $\begin{array}{l}\text { Q5 } \\
\text { most walkable }\end{array}$ \\
\hline 2003-2004 & 4206 & 14 & $930(13.5)$ & $863(13.5)$ & 937 (17.2) & $827(13.4)$ & 649 (12.2) \\
\hline 2007-2008 & 5202 & 19.9 & $1131(20.5)$ & $1044(18.7)$ & 1030 (20.6) & 1059 (20.9) & $938(18.6)$ \\
\hline 2009-2010 & 4200 & 17 & 911 (15.9) & 905 (18.9) & $818(16.6)$ & $836(16.4)$ & $730(17.4)$ \\
\hline Q1 (least deprived) & 5838 & 19.3 & 2235 (33.1) & 1405 (22.2) & $859(14.7)$ & $606(11.5)$ & 733 (14.3) \\
\hline 2 & 5143 & 18.3 & $1410(23.9)$ & $1224(20.5)$ & 1055 (19.3) & $816(14.0)$ & $638(13.2)$ \\
\hline 3 & 5085 & 19.4 & $1114(20.5)$ & $1117(20.0)$ & $1032(20.4)$ & 1042 (18.3) & $780(17.7)$ \\
\hline 4 & 5016 & 19.4 & $765(13.0)$ & $971(18.6)$ & $1226(23.3)$ & $1183(20.8)$ & $871(21.6)$ \\
\hline
\end{tabular}

BMI, body mass index; CCHS, Canadian Community Health Survey.

and 34 years. Hence, while the age distribution across quintiles was not drastically different, Q5 neighbourhoods (most walkable) tended to be slightly younger while Q1 neighbourhoods (least walkable) slightly older. Education and income levels were evenly distributed across neighbourhoods, Q1 (least walkable) neighbourhoods tended to be slightly more educated and higher-income households. Walkability was inversely associated with martial status, with more partnered households in lower versus higher quintiles. There were also higher smoking rates in Q5 neighbourhoods (most walkable) versus other quintiles. Those in Q1 neighbourhoods (least walkable) tended to be more overweight and obese than Q5 (most walkable) residents (table 1). For example, those in Q5 neighbourhoods (most walkable) had between $3.6 \%$ and $7.5 \%$ higher proportion of 'normal' healthy body mass index (BMI) versus other quintiles. Less walkable neighbourhoods also tended to have noticeably lower deprivation versus more walkable neighbourhoods, which had greater deprivation.

\section{Incidence risk of MM}

The time to event analysis was conducted for individuals between the ages of 20 and 64 years and 65 and 95 years who were not multimorbid (living with less than two chronic conditions) at the time of survey (CCHS), residing within one of the walkability quintiles (Q1-Q5), between the year 2000 and 2012. The model was run twice, initially with the two-count definition of MM and subsequently the three-count definition as the outcome (ie, event). In the final adjusted model, sex, education, income, marital status, smoking, stress, PA, self-perception of health, CCHS cycle and material deprivation were included.

In the two-condition model (table 2), 10792 (40.2\%) experienced the event; 378 (1.4\%) died, $15710(58.4 \%)$ were censored. The median follow-up time was 3208 days (8.8 years). Females were at a $12 \%$ higher risk $(\mathrm{p}=0.0011 ; \mathrm{HR}=1.12 ; 95 \% \mathrm{CI}: 1.05$ to 1.20$)$ for $\mathrm{MM}$, relative to males. Ageing was highly significant across deprivation quintiles for MM, with subsequent greater risk in each age band; 35-49 years old ( $\mathrm{HR}=1.63$; $95 \% \mathrm{CI}$ : 1.50 to 1.76$)$ and $50-64$ years (HR=2.78; 95\% CI: 2.53 to 3.06). Income was marginally associated with MM, with the greatest risk observed in the lower-middle-income bracket, making $\$ \mathrm{C} 40000$ to $\$ \mathrm{C} 59999$ per year $(\mathrm{p}=0.0578$; $\mathrm{HR}=1.12 ; 95 \% \mathrm{CI}: 1.00$ to 1.25$)$. There was an increased risk for MM associated with worsening self-perception of health. With respect to walkability, those in the bottom two quintiles Q1 ( $\mathrm{p}=0.0230 ; \mathrm{HR}=1.14 ; 95 \% \mathrm{CI}$ : 1.02 to 1.28) and $\mathrm{Q}_{2}(\mathrm{p}=0.0450 ; \mathrm{HR}=1.13 ; 95 \% \mathrm{CI}: 1.00$ to 1.27$)$ had the greatest risk for MM relative to Q5 neighbourhoods (most walkable). Despite the non-significance of Q3 and Q4, the direction and relationship between walkability and MM are evident. In the older age groups (6595 years), smoking was associated with a $26 \%$ increased risk for $\mathrm{MM}(\mathrm{p}=0.0101 ; \mathrm{HR}=1.26 ; 95 \% \mathrm{CI}$ : 1.06 to 1.49$)$ relative to non-smokers. Neighbourhood walkability showed no protective benefit in this context for older adults (65-95 years) (online supplemental table 1 ).

In the alternate model (online supplemental table 2), everything was kept the same except for the outcome variable and event. For three-count MM, 5021 (16.68\%) people experienced the event; $710(2.64 \%)$ died and $21149(78.68 \%)$ were censored. The median follow-up was 3850 days (10.5 years). Sex was not a risk factor for high morbidity. All variations of self-perceived health with exception of 'very good' were significant. Walkability showed no association with MM within the highmorbidity model. Smoking remained significant in the three-morbidity model ( $\mathrm{p}=0.0092 ; \mathrm{HR}=1.32 ; 95 \% \mathrm{CI}: 1.07$ to 1.62$)$. Other study variables showed no significant association with MM.

We conducted a stratified analysis to examine study variables in relation to material deprivation (figure 1, table 3). Material deprivation has shown in previous studies to be strongly associated with MM, ${ }^{5} 31$ enabling greater isolation of study variables. Within the 20 -year-old 
Table 2 HR of neighbourhood walkability quintiles - ages 20-64 years

\begin{tabular}{|c|c|c|c|c|}
\hline & Unadjusted HR & Unadjusted $p$ value & Adjusted HR & Adjusted $\mathrm{p}$ value \\
\hline \multicolumn{5}{|l|}{ Sex } \\
\hline Male & $1.00(-)$ & - & $1.00(-)$ & - \\
\hline Female & 1.13 (1.06 to 1.20$)$ & $<0.0001$ & $1.12(1.05$ to 1.20$)$ & 0.0011 \\
\hline \multicolumn{5}{|l|}{ Age, years } \\
\hline $20-34$ & $1.00(-)$ & - & $1.00(-)$ & - \\
\hline $35-49$ & 1.70 (1.58 to 1.83$)$ & $<0.0001$ & 1.63 (1.50 to 1.76$)$ & $<0.0001$ \\
\hline $50-64$ & 2.97 (2.73 to 3.23 ) & $<0.0001$ & 2.78 (2.53 to 3.06$)$ & $<0.0001$ \\
\hline \multicolumn{5}{|l|}{ Education } \\
\hline Less than high school & $1.00(-)$ & - & $1.00(-)$ & - \\
\hline High school completed & 0.80 (0.68 to 0.94$)$ & 0.0079 & 0.82 (0.69 to 0.98$)$ & 0.0287 \\
\hline Some post-secondary & 0.69 (0.57 to 0.84$)$ & 0.0002 & 0.79 (0.64 to 0.97$)$ & 0.0245 \\
\hline Post-secondary completed & 0.71 (0.62 to 0.82$)$ & $<0.0001$ & 0.82 (0.71 to 0.96$)$ & 0.0130 \\
\hline \multicolumn{5}{|l|}{ Income group } \\
\hline 0-\$C19999 & 1.02 (0.89 to 1.18$)$ & 0.7523 & 0.85 (0.73 to 0.99$)$ & 0.0321 \\
\hline \$C20 000-\$C39999 & 1.00 (0.89 to 1.12$)$ & 0.9751 & 0.89 (0.79 to 1.01$)$ & 0.0690 \\
\hline \$C40 000-\$C59999 & 1.24 (1.11 to 1.37$)$ & $<0.0001$ & $1.12(1.00$ to 1.25$)$ & 0.0578 \\
\hline$\$ C 60$ 000-\$C79999 & 1.15 (1.06 to 1.24$)$ & 0.0008 & 0.98 (0.89 to 1.08$)$ & 0.7107 \\
\hline$\$ C 80000+$ & $1.00(-)$ & - & $1.00(-)$ & - \\
\hline \multicolumn{5}{|l|}{ Marital status } \\
\hline Married/common law & $1.00(-)$ & - & $1.00(-)$ & - \\
\hline Widow/separated/divorced & 1.24 (1.12 to 1.37$)$ & $<0.0001$ & 1.08 (0.97 to 1.21$)$ & 0.1780 \\
\hline Single & 0.62 (0.58 to 0.67$)$ & $<0.0001$ & 0.96 (0.88 to 1.05$)$ & 0.3556 \\
\hline \multicolumn{5}{|l|}{ Smoker type } \\
\hline Regular/former & 1.14 (1.07 to 1.21$)$ & $<0.0001$ & 1.05 (0.99 to 1.13$)$ & 0.1188 \\
\hline Occasional/non-smoker & $1.00(-)$ & - & $1.00(-)$ & - \\
\hline \multicolumn{5}{|l|}{ Physical activity } \\
\hline Active & $1.00(-)$ & - & $1.00(-)$ & - \\
\hline Inactive & $1.13(1.06$ to 1.20$)$ & 0.0001 & 1.01 (0.95 to 1.08$)$ & 0.7533 \\
\hline \multicolumn{5}{|l|}{ Life stress } \\
\hline None/low stress & $1.00(-)$ & - & $1.00(-)$ & - \\
\hline High stress & 1.26 (1.07 to 1.47$)$ & 0.0044 & 1.09 (0.92 to 1.30$)$ & 0.3210 \\
\hline \multicolumn{5}{|l|}{ Self-perceived health } \\
\hline Excellent & $1.00(-)$ & - & $1.00(-)$ & - \\
\hline Very good & 1.11 (1.03 to 1.20$)$ & 0.0070 & 1.15 (1.06 to 1.26$)$ & 0.0009 \\
\hline Good & 1.34 (1.23 to 1.46$)$ & $<0.0001$ & $1.37(1.25$ to 1.50$)$ & $<0.0001$ \\
\hline Fair & 2.08 (1.78 to 2.42 ) & $<0.0001$ & 1.94 (1.65 to 2.28$)$ & $<0.0001$ \\
\hline Poor & 2.11 (1.56 to 2.85 ) & $<0.0001$ & $1.82(1.32$ to 2.51$)$ & 0.0003 \\
\hline \multicolumn{5}{|l|}{$\mathrm{CCHS}$ cycles } \\
\hline Years (2000-2012) & 0.91 (0.90 to 0.93$)$ & $<0.0001$ & 0.90 (0.88 to 0.93$)$ & $<0.0001$ \\
\hline \multicolumn{5}{|l|}{ Walkability Index (DA-Ivl) } \\
\hline Q1 (least walkable) & 1.20 (1.08 to 1.35$)$ & 0.0010 & 1.14 (1.02 to 1.28$)$ & 0.0230 \\
\hline 2 & 1.19 (1.07 to 1.34$)$ & 0.0021 & $1.13(1.00$ to 1.27$)$ & 0.0450 \\
\hline 3 & 1.20 (1.07 to 1.35$)$ & 0.0014 & 1.08 (0.96 to 1.21$)$ & 0.1980 \\
\hline 4 & $1.13(1.00$ to 1.27$)$ & 0.0414 & 1.07 (0.95 to 1.21$)$ & 0.2689 \\
\hline Q5 (most walkable) & $1.00(-)$ & - & $1.00(-)$ & - \\
\hline
\end{tabular}

CCHS, Canadian Community Health Survey. 


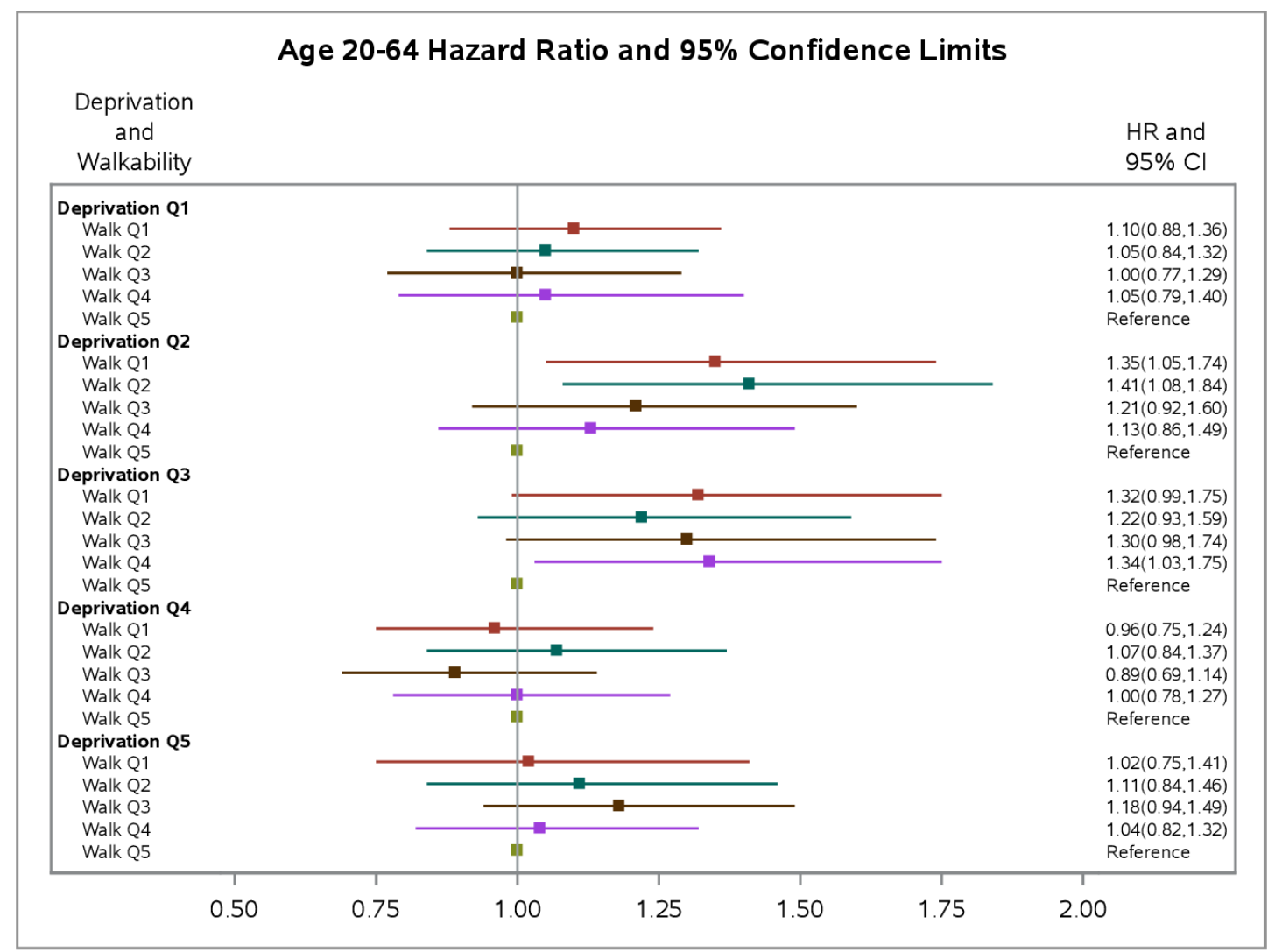

Figure 1 HR for multimorbidity by neighbourhood walkability and deprivation quintiles - ages 20-64 years.

to 64-year-old cohort, Q1 (least deprived) and Q4, Q5 (most deprived) neighbourhoods showed no significant association with neighbourhood walkability. In deprivation Q2, the two least walkable neighbourhoods showed significantly higher risk for MM walkability-Q1 $(\mathrm{p}=0.0188$; HR=1.35, 95\% CI: 1.05 to 1.74$)$ and walkability-Q2（p=0.0112; HR=1.41; 95\% CI: 1.08 to 1.84$)$. The remaining quintiles showed a clear gradient between increased walkability and decreased risk for MM. Deprivation $\mathrm{Q} 3$ was also statistically significant in walkability $\mathrm{Q} 4$ ( $\mathrm{p}=0.0322 ; \mathrm{HR}=1.34,95 \%$ CI: 1.03 to 1.75$)$. Walkability Q1 $(\mathrm{p}=0.0568$; HR=1.32, 95\% CI: 0.99 to 1.75$)$ was not significant, however, results were mixed overall. High stress was a significant risk factor for $\mathrm{MM}$ in the most deprived neighbourhoods $(\mathrm{p}=0.0078 ; \mathrm{HR}=1.63 ; 95 \%$ CI: 1.14 to 2.33). The analysis was replicated for those $65-95$ years of age and did not reveal anything of note (online supplemental table 3 and 4).

\section{DISCUSSION}

The results of this study demonstrate a statistically significant association between neighbourhood walkability, material deprivation and incidence of MM. In the 20-year-old to 64-year-old cohort, the adjusted model demonstrated that residents in the least walkable neighbourhoods (Q1 and Q2) were at up to $14 \%$ increased risk for MM over the observation period. A similar trend was observed in the stratified analysis, although to a lesser extent. The significance of this association was observed primarily in less walkable neighbourhoods (Q2). Despite the lack of statistical significance in walkability Q3 and Q4, the direction of the hypothesised association was observed in those quintiles. A dose-response between increasing deprivation and walkability, and vice versa was noted. Those in less walkable neighbourhoods (Q1) were less deprived and more affluent; therefore, it is possible that the negative health risk of low walkability and the positive health benefits of low deprivation are cancelling out each other. Further research is needed to investigate these observed relationships. Another explanation could be that individuals in Q1 and Q5 neighbourhoods are typically more active as shown in other studies. ${ }^{940}$ It might also be the case that those least deprived are getting more benefit out of walkability than those more deprived. In the stratified analysis, we see that deprivation Q2 is showing a dose-response to walkability, as deprivation increases so too does the risk for MM. In Q3 we saw a mixed effect, while in Q4 and Q5 (most deprived), we saw the least association, therefore, deprivation could be cancelling out the benefits of walkability in the most deprived neighbourhoods. We know from a previous study ${ }^{31}$ that material deprivation is strongly associated with increased prevalence of MM.

Worthy of note, summary statistics and the univariate model showed a clear gradient and dose-response between walkability and BMI. This was expected as the relationship between these two variables has been studied extensively. ${ }^{9} 101828-303641$ We included BMI (ie, overweight 


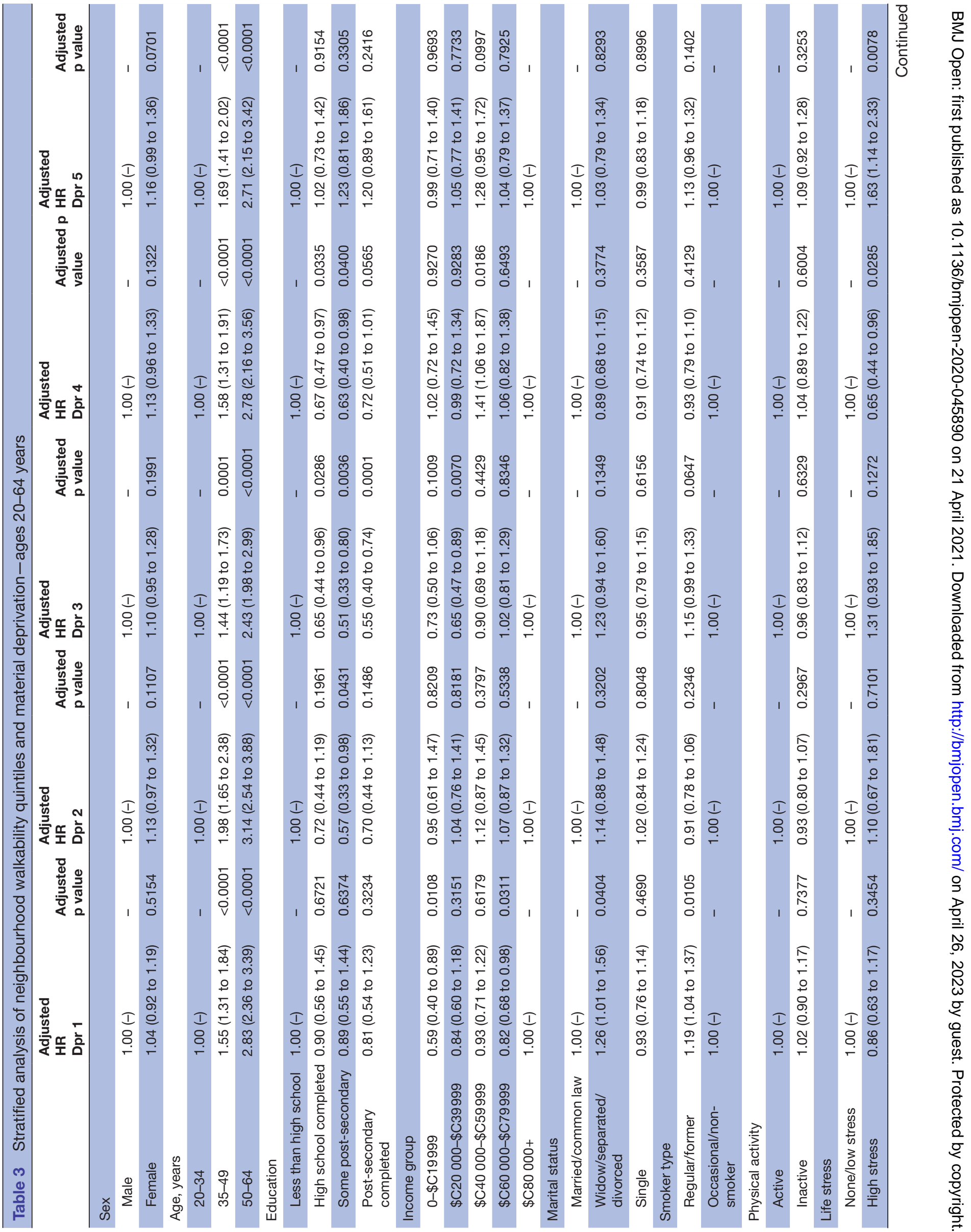


and obesity) in table 1 and univariate analysis, however, as we expect it to be on the causal path (as a 'risk condition') it was dropped from the multivariable survival analysis.

This study has strengths and limitations. We used Cox's proportional hazard modelling because of the robust semiparametric method for calculating the probabilities of survival, while simultaneously adjusting for other possibly influential variables. ${ }^{42}$ Opting for a retrospective cohort design allowed for analysing large sample sizes quickly and economically. Bootstrap (500 times) weights were used to help fine-tune the CIs that can potentially allow for greater generalisability of findings to the wider population. Some caution regarding the interpretation of results is warranted, as survey cycles were merged, therefore, creating an 'artificial' population made up of different respondents at different times. ${ }^{43}$ However, it is not overly concerning within the context of this study, given the study design, and indexing of everyone based on their own survey date. Lastly, well-designed observational studies may be one of the best sources of evidence for this area of research, as randomised controlled trials are neither ethical nor feasible. ${ }^{45}$

There are limitations to this study design. We were unable to factor in and control for all possible covariates and confounders (eg, prenatal, early life and childhood factors, social support) with respect to the literature. The Walkability Index does not factor in certain features from the literature (eg, lighting, low crime/neighbourhood safety) into their walkability scores. This means that the scores are not a perfect representation of walkable neighbourhoods. Certain DAs were also missing from the index, possibly due to missing data sources, which excludes residents from those areas. Also, walkability was only available for one timepoint, covering Toronto and major municipalities but not all of Ontario. This also means that we were unable to account for changes in walkability in Toronto and neighbouring regions as they continue to grow and develop. We were also unable to track and account for residents moving during the study period, from high-low or low-high walkability neighbourhoods. However, the index has been used and validated in the past, ${ }^{10} 36$ shown to be stable over time and associated with increased cycling, public transit use and reduced dependence on automobiles. ${ }^{9}$ The model is also likely underpowered and therefore a larger sample size may resolve a possible power issue. This is especially the case in the stratified analysis as the data was further subdivided into deprivation quintiles. Nevertheless, we found promising indications that neighbourhood walkability may be protective against $\mathrm{MM}$ and that persons living in the least deprived households are possibly benefitting the most.

Environmental factors and built environmental dimensions such as neighbourhood walkability discussed in this study will continue to be important areas for research in reducing preventable chronic diseases and MM in the population. As discussed previously, transport is a key dimension to be considered when promoting widespread PA in the population for disease prevention. Features of 
the built environment that promote greater public transit use, walking and other forms of active transport can help the population be more active and meet PA recommendations. Despite study limitations, there are sufficient findings here to justify further investigations into the built environment and transport dimensions as part of ongoing efforts towards curbing preventable chronic diseases and promoting strategies for population-level prevention.

\section{Author affiliations}

${ }^{1}$ Dalla Lana School of Public Health, University of Toronto, Toronto, Ontario, Canada ${ }^{2}$ Institute for Clinical Evaluative Sciences, Toronto, Ontario, Canada

${ }^{3}$ St Michael's Hospital Li Ka Shing Knowledge Institute, Toronto, Ontario, Canada

${ }^{4}$ Institute for Better Health, Trillium Health Partners, Mississauga, Ontario, Canada

${ }^{5}$ Department of Research Design and Biostatistics, Sunnybrooke Research Institute, Toronto, Ontario, Canada

${ }^{6}$ Biostatistics, Institute for Clinical Evaluative Sciences, Toronto, Ontario, Canada ${ }^{7}$ Bridgepoint Collaboratory for Research and Innovation, Lunenfeld-Tanenbaum Research Institute, Toronto, Ontario, Canada

Acknowledgements This study was supported by the Institute for Clinical Evaluative Sciences (ICES), which is funded by an annual grant from the Ontario Ministry of Health and Long-Term Care (MOHLTC). The opinions, results and conclusions reported in this paper are those of the authors and are independent from the funding sources. No endorsement by ICES or the Ontario MOHLTC is intended or should be inferred.

Contributors This study was designed and conceptualised by JSM, RHG, KK, AK and RU. The manuscript was written by JSM. All contributing authors assisted in the design and review of the manuscript.

Funding The authors have not declared a specific grant for this research from any funding agency in the public, commercial or not-for-profit sectors.

Competing interests None declared.

Patient consent for publication Not required.

Ethics approval This study was conducted in accordance with Research Ethics Board guidelines and policies at the University of Toronto. Studies conducted at ICES that fall under section 45 of Ontario's PHIPA are legally exempt from REB review, for purposes of evaluating and monitoring health systems. Furthermore, all such studies carried out within ICES are subject to a privacy impact assessment and approval from ICES Privacy and Legal Office prior to launch. The protocol for this study was approved by ICES and the data sufficiently deidentified and small cells suppressed to protect privacy. All analyses for this study were conducted in a secure facility at ICES Central.

Provenance and peer review Not commissioned; externally peer reviewed.

Data availability statement No data are available. The data presented in this study are housed at ICES and are not publicly available due to privacy agreements.

Supplemental material This content has been supplied by the author(s). It has not been vetted by BMJ Publishing Group Limited (BMJ) and may not have been peer-reviewed. Any opinions or recommendations discussed are solely those of the author(s) and are not endorsed by BMJ. BMJ disclaims all liability and responsibility arising from any reliance placed on the content. Where the content includes any translated material, BMJ does not warrant the accuracy and reliability of the translations (including but not limited to local regulations, clinical guidelines, terminology, drug names and drug dosages), and is not responsible for any error and/or omissions arising from translation and adaptation or otherwise.

Open access This is an open access article distributed in accordance with the Creative Commons Attribution Non Commercial (CC BY-NC 4.0) license, which permits others to distribute, remix, adapt, build upon this work non-commercially, and license their derivative works on different terms, provided the original work is properly cited, appropriate credit is given, any changes made indicated, and the use is non-commercial. See: http://creativecommons.org/licenses/by-nc/4.0/.

ORCID iDs

John Sina Moin http://orcid.org/0000-0002-0692-5552

Richard H Glazier http://orcid.org/0000-0002-7952-8320
Kerry Kuluski http://orcid.org/0000-0002-6377-6653

Ross Upshur http://orcid.org/0000-0003-1128-0557

\section{REFERENCES}

1 Feely A, Lix LM, Reimer K. Estimating multimorbidity prevalence with the Canadian chronic disease surveillance system. Health Promot Chronic Dis Prev Can 2017;37:215-22.

2 Marengoni A, Angleman S, Melis R, et al. Aging with multimorbidity: a systematic review of the literature. Ageing Res Rev 2011;10:430-9.

3 Hajat C, Stein E. The global burden of multiple chronic conditions: a narrative review. Prev Med Rep 2018;12:284-93.

4 Marengoni A, von Strauss E, Rizzuto D, et al. The impact of chronic multimorbidity and disability on functional decline and survival in elderly persons. A community-based, longitudinal study. J Intern Med 2009;265:288-95.

5 Thavorn K, Maxwell CJ, Gruneir A, et al. Effect of socio-demographic factors on the association between multimorbidity and healthcare costs: a population-based, retrospective cohort study. BMJ Open 2017;7:e017264

6 Wister A, Kendig H, Mitchell B, et al. Multimorbidity, health and aging in Canada and Australia: a tale of two countries. BMC Geriatr 2016;16:163.

7 Canada PHAo. The economic burden of illness in Canada, 2010 custom report generator. her Majesty the Queen in right of Canada, 2010. Available: https://cost-illness.canada.ca/index.php

$8 \mathrm{PHO}$. The burden of chronic diseases in Ontario: key estimates to support efforts in prevention. $\mathrm{CCO}$ and Ontario agency for health protection and promotion (public health Ontario) 2019

9 Creatore MI, Glazier RH, Moineddin R, et al. Association of neighborhood Walkability with change in overweight, obesity, and diabetes. JAMA 2016;315:2211-20.

10 Glazier RH, Creatore MI, Weyman JT, et al. Density, destinations or both? A comparison of measures of walkability in relation to transportation behaviors, obesity and diabetes in Toronto, Canada. PLoS One 2014;9:e85295.

11 Sallis JF, Floyd MF, Rodríguez DA, et al. Role of built environments in physical activity, obesity, and cardiovascular disease. Circulation 2012;125:729-37.

12 Sharma AM, Lau DCW. Obesity and type 2 diabetes mellitus. Can $J$ Diabetes 2013;37:63-4.

13 Smith AD, Crippa A, Woodcock J, et al. Physical activity and incident type 2 diabetes mellitus: a systematic review and doseresponse meta-analysis of prospective cohort studies. Diabetologia 2016;59:2527-45.

14 Rundle AG, Heymsfield SB. Can Walkable urban design play a role in reducing the incidence of obesity-related conditions? JAMA 2016:315:2175-7.

15 WHO. Preventing chronic diseases : a vital investment: WHO global report. Geneva Switzerland: World Health Organization, 2005.

16 WHO. Japan-WHO meeting on Multisectoral interventions for Ncd prevention. Manila, Philippines: World Health Organization, 2010.

17 Canada S. Canadian health measures survey: activity monitor data 2017.

18 Booth GL, Creatore MI, Moineddin R, et al. Unwalkable neighborhoods, poverty, and the risk of diabetes among recent immigrants to Canada compared with long-term residents. Diabetes Care 2013;36:302-8.

19 Pettee Gabriel KK, Morrow JR, Woolsey AL. Framework for physical activity as a complex and multidimensional behavior. $J$ Phys Act Health 2019;9 Suppl 1:S11-18.

20 Khaing Nang EE, Khoo EYH, Salim A, et al. Patterns of physical activity in different domains and implications for intervention in a multi-ethnic Asian population: a cross-sectional study. BMC Public Health 2010;10:644.

21 Norwood P, Eberth B, Farrar S, et al. Active travel intervention and physical activity behaviour: an evaluation. Soc Sci Med 2014:113:50-8

22 Wallmann-Sperlich B, Froboese I. Physical activity during work, transport and leisure in Germany--prevalence and sociodemographic correlates. PLoS One 2014;9:e112333.

23 Tudor-Locke C, Bittman M, Merom D, et al. Patterns of walking for transport and exercise: a novel application of time use data. Int $J$ Behav Nutr Phys Act 2005;2:5.

24 Baker PRA, Francis DP, Soares J, et al. Community wide interventions for increasing physical activity. Cochrane Database Syst Rev 2015;1:CD008366.

25 Smith M, Hosking J, Woodward A, et al. Systematic literature review of built environment effects on physical activity and active transport 
- an update and new findings on health equity. Int $J$ Behav Nutr Phys Act 2017:14:158

26 Xiao C, Goryakin Y, Cecchini M. Physical activity levels and new public transit: a systematic review and meta-analysis. Am J Prev Med 2019;56:464-73.

27 Witten K, Blakely T, Bagheri N, et al. Neighborhood built environment and transport and leisure physical activity: findings using objective exposure and outcome measures in New Zealand. Environ Health Perspect 2012;120:971-7.

28 Loo CKJ, Greiver M, Aliarzadeh B, et al. Association between neighbourhood walkability and metabolic risk factors influenced by physical activity: a cross-sectional study of adults in Toronto, Canada. BMJ Open 2017;7:e013889.

29 Omura JD, Ussery EN, Loustalot F, et al. Walking as an opportunity for cardiovascular disease prevention. Prev Chronic Dis 2019;16:E66.

30 Sarkar C, Webster C, Gallacher J. Neighbourhood walkability and incidence of hypertension: findings from the study of 429,334 UK Biobank participants. Int J Hyg Environ Health 2018;221:458-68.

31 Moin JS, Moineddin R, Upshur REG. Measuring the association between marginalization and multimorbidity in Ontario, Canada: a cross-sectional study. J Comorb 2018;8:2235042X1881493.

32 Canada S. Illustrated glossary: catalogue no. 92-195-X. Ottawa 2017.

33 Matheson FI, Dunn JR, Smith KLW. Development of the Canadian marginalization index: a new tool for the study of inequality/ Elaboration de l'indice de marginalisation Canadien: un nouvel outil d'Etude des inegalites. Canadian Journal of Public Health 2012;103:S12+.

34 Roberts KC, Rao DP, Bennett TL, et al. Prevalence and patterns of chronic disease multimorbidity and associated determinants in Canada. Health Promot Chronic Dis Prev Can 2015;35:87-94.
35 Béland Y. Canadian community health survey--methodological overview. Health Rep 2002;13:9-14.

36 et alGlazier RH, Weyman JT, Creatore MI. A geographic approach for developing and validating urban Walkability indices Toronto community health profiles, 2012. Available: http://www.torontohealt hprofiles.ca/a documents/aboutTheData/12 1_ReportsAndPapers Walkability_WKB_2012.pdf

37 Fortin M, Stewart M, Poitras M-E, et al. A systematic review of prevalence studies on multimorbidity: toward a more uniform methodology. Ann Fam Med 2012;10:142-51.

38 Mondor L, Wodchis WP. Concept title: multimorbidity 2018.

39 Pefoyo AJK, Bronskill SE, Gruneir A, et al. The increasing burden and complexity of multimorbidity. BMC Public Health 2015;15:415.

40 Chiu M, Shah BR, Maclagan LC, et al. Walk Score $\AA$ and the prevalence of utilitarian walking and obesity among Ontario adults: a cross-sectional study. Health Rep 2015;26:3-10.

41 Tudor-Locke C. Steps to better cardiovascular health: how many steps does it take to achieve good health and how Confident are we in this number? Curr Cardiovasc Risk Rep 2010;4:271-6.

42 Smith T, Smith B. Survival analysis and the application of Cox's proportional hazards modeling using SAS. Statistics, Data Analysis, and Data Mining 2000

43 Thomas S, Wannell B. Combining cycles of the Canadian community health survey. Health Rep 2009;20:53-8.

44 Alper BS, Haynes RB. EBHC pyramid 5.0 for accessing preappraised evidence and guidance. Evid Based Med 2016;21:123-5.

45 Evans D. Hierarchy of evidence: a framework for ranking evidence evaluating healthcare interventions. J Clin Nurs 2003;12:77-84. 